JPDN ISSN 2579-6461 (Online) ISSN 2460-6324 (Print)

Jurnal Pendidikan Dasar Nusantara

Volume 5 | Nomor 2 | Januari 2020|

DOI: https://doi.org/10.29407/jpdn.v5i2.14006

\title{
PEMAHAMAN SISWA TERHADAP PEMBELAJARAN BAHASA USING SEBAGAI WARISAN BUDAYA LOKAL BANYUWANGI DI SDN 1 SUMBERBARU
}

\author{
Karimatus Saidah $^{1)}$, Rima Trianingsih ${ }^{2}$ \\ ${ }^{1}$ FKIP, Universitas Nusantara PGRI Kediri (penulis 1) \\ email: Karimatus@unpkediri.ac.id \\ ${ }^{2}$ SDN 1 Sumberbaru (penulis 2) \\ email: rimatrian@gmail.com \\ No Handphone: +6285257315651
}

\begin{abstract}
Abstrak: Penelitian ini bertujuan untuk (1) mengetahui bagaimana pelaksanaan pembelajaran Bahasa Using yang dilksanakan di SDN 1 Sumberbaru (2) Menjabarkan kurikulum pembelajaran Bahasa Using di tingkat sekolah dasar (3) Mengetahui bagaimana pemahaman siswa terhadap pembelajaran Bahasa Using yang dilaksanakan khususnya di kelas V. Metodologi penelitian yang digunakan adalah dengan menggunakan pendekatan kualitatif dengan desain penelitian etnografi tipe studi kasus. Teknik pengumpulan data yang digunakan adalah observasi kegiatan siswa, wawancara dan dokumentasi hasil belajar siswa pada mata pelajaran Bahasa Using. Teknik analisis data yang digunakan yaitu melalui pengumpulan data, reduksi data, revisi data dan penarikan kesimpulan. Hasil penelitian menunjukkan bahwa pelaksanaan pembelajaran di SDNI Sumberbaru dilaksanakan setiap dua minggu sekali berselang seling dengan pembelajaran Bahasa jawa. Guru menggunakan metode ceramah dan penugasan. Pembelajaran dilakukan dengan menggunakan buku Panduan yang telah disediakan oleh sekolah. Dalam satu semester siswa harus menguasai tiga kompetensi pada aspek pengetahuan dan tiga kompetensi pada aspek keterampilan. Materi pembelajaran Bahasa Using tesebut meliputi bacaan, sastra dan tata Bahasa yang mengangkat berbagai budaya Using seperti kesenian, makanan khas, puisi dan sebagainya. Hasil wawancara menunjukkan bahwa siswa dapat berkomunikasi aktif menggunakan Bahasa Using namun kurang memahami bacaan maupun sastra dalam pembelajaran Bahasa Using. Hasil dokumentasi nilai ujian tengah semester menunjukkan rata-rata nilai siswa yaitu 39 sedangkan kriteria ketuntasan minimalnya adalah 75 . Faktor penyebabnya adalah ada bebebrapa guru (khususnya kelas V) yang bukan orang asli Using sehingga masih mempelajari dan mengembangkan metode pembelajaran yang tepat serta struktur Bahasa Using yang ditampilkan dalam pembelajaran masih di rasa asing bagi siswa.
\end{abstract}

Kata kunci: Bahasa Using, Siswa, Kearifan local Banyuwangi.

\section{THE STUDENT UNDERSTANDING TRHOUGH USING LANGUAGE AS LOCAL CULTURE OF BANYUWANGI AT SDN 1 SUMBERBARU}




\section{Karimatus, Rima, Pemahaman Siswa Terhadap Pembelajaran.}

This study is aim to (1) know how learning of Using is performed in SDN 1 Sumberbaru.(2)explored the curriculum of Using learning in the elementary school. (3) To know student Understanding of Using learning especially is done in fifth grade. The research methodology used is a qualitative approach to the design of ethnographic type Metode ( $\pm 10-20 \%)$ of case study. The data collection techniques used are observation, interviews and documenting results of learning Using. The data analysis techniques used are through data collection, data reduction, data revisions and deductions. The result of this studies showed that Using learning is done in SDN 1 Sumberbaru in two weeks interlude with Javanese learning. Teacher have used methods of talks and assignments. Learning are done using a guidebook provide by the school institutions. The Using subject material includes reading, literature and grammar that promote Using culture like arts, signature dish,poem, etc. Interview resulr indicate that students can communicate actively in Using. But they don't know much about literature and grammar. The result of documentation on midterm scores showed average score is 39 with the minimal 75 performance criteria. The reason of this case is teache are not Using so they still learning and developing the right method to teach Using. Another reason Using grammar and literature to be thaught is still a foreign to students.

Keywords: the Using language, Student, Local culture Banyuwangi

\section{PENDAHULUAN}

Banyuwangi merupakan salah satu kabupaten yang terletak di ujung timur provinsi Jawa Timur. Wilayah Banyuwangi pada masa kerajaan termasuk wilayah kerajaan Blambangan. Hingga saat ini Banyuwangi masih di huni oleh masyarakat asli yang hidup dan tinggal secara turun temurun yang sering di sebut dengan Orang Using. Menurut Arifin dan Ilham (dalam Bahtiar, Syamsu Hadi, 2018) Kata Using berarti "tidak" yang kemudian dimaknai sebagai orang-orang yang tidak ikut mengungsi ketika terjadi perang "Puputan Bayu" Sehingga tetap menempati wilayah Blambangan.

Orang Using mmemiliki keragaman budaya yang terwujud dalam berbagai adat istiadat, kesenian maupun Bahasa. Adat istiadat terwujud dalam bentuk bangunan adat, benda-benda adat maupun upacara adat seperti upacara adat Seblang, Tumpeng sewu dan lain sebagainya. Wujud kesenian khas Using yang saat ini masih dilestarikan yaitu tari gandrung. Karakteristik orang Using diantaranya adalah tepo seliro, mawas diri, mengutamakan kebersamaan, tidak mudah menyalahkan sekitar, sungkan, meyakini karma sehingga berhati-hati dalam bersikap, memegang teguh weluri yaitu wejangan atau 
Karimatus, Rima, Pemahaman Siswa Terhadap Pembelajaran. petuah, mencintai kesenian, dan sebagainya(Hanafi, Hidayah, \& At, 2018)

Orang Using dalam kehidupan sehari-harinya menggunakan Bahasa yang dikenal dengan Bahasa Using. Bahasa Using sesuai dengan perda banyuwangi yang di susun pada tahun 2007 diartikan sebagai Bahasa yang di tandai dengan ciri kedaerahan, diwariskan dan dipelihara turun temurun, berkembang bersama tumbuhnya cikal bakal masyarakat banyuwangi (Arps, 2010)). Ciri khas Bahasa Banyuwangi adalah tidak memiliki tingkatan bahasa yang dikenal dalam Bahasa jawa secara luas. Akan tetapi menurut Saputra, (2007) secara umum Bahasa dan budaya Using pada batasan tertentu dapat dikatakan memiliki kemiripan dengan Bahasa Jawa pada umumnya, namun secara khusus Orang Using tidak mengakui bahwa Bahasa yan mereka gunakan sehari hari adalah Bahasa Jawa, melainkan merupakan Bahasa Using itu sendiri. Pernyataan ini diperkuat kengan kenyataan yang terdapat di lapangan, bahwa dalam pergaulan seharihari Bahasa Using tidak memiliki Unggah Ungguh (basa krama) yang menyangkut domain tingkat sosial maupun tingkat kekerabatan. Dalam bahasa jawa terdapat tingkatan bahasa ngoko dan krama alus, dimana krama alus di bagi menjadi empat leksikon yaitu madya, inggil, netral dan afiks krama inggil (Damariswara,2016). Tingkatan ini tidekan dalam bahasa Using Kecuali untuk kata "rika" dan "Ndika" (keduanya memiliki arti kamu) yang digunakan untuk berkomunikasi dengan orang yang dihormati.

Seiring dengan perubahan sosial dan perkembangan zaman Banyuwangi kini tidak hanya dihuni oleh Orang Using, melainkan juga banyak pendatang dari luar Banyuwangi, seperti dari Madura, Bali, Jember dan daerah sekitarnya. Menurut Arps, (2010) Separuh lebih dari 1,5 juta penduduk Banyuwangi sekarang adalah keturunan imigran yang mulai indah ke daerah ini dalam jumlah yang cukup besar. Masyarakat Banyuwangi selain menggunakan Bahasa Indonesia juga menggunakan Bahasa Jawa, atau Madura, maupun penutur Bahasa lain seperti Bahasa Bali dan melayu. Hanya sekitar 500.000-750.000 penduduk Banyuwangi yang biasa menggunakan ragam Bahasa yang kita sebut dengan Bahasa Using.

Berdasarkan laporan Sodiqin (2018) menyatakan bahwa, bagi orang Using sendiri, Bahasa Using mulai ditinggalkan. Hanya beberapa daerah tertentu yang masih menggunakan Bahasa Using sebagai Bahasa sehari-hari. Sementara di kota Banyuwangi sendiri Bahasa ini justru jarang sekali digunakan dan bahkan mulai ditinggalkan. Sedangkan menurut Sari (Dalam Sutarto, 2006), wilayah pemukiman orang Using makin 
Karimatus, Rima, Pemahaman Siswa Terhadap Pembelajaran. lama makin mengecil. Dari 21 kecamatan saat ini tingga 9 kecamatan yang masih menjadi kantong kebudayaan orang Using. Kesembilan kecamatan itu diantaranya adalah Banyuwangi, Giri, Glagah, Rogojampi, Singojuruh, Kabat, Songgon, Cluring dan Genteng.

Dalam Peraturan gubernur jawa timur no 19 tahun 2014 tentang mata pelajaran Bahasa daerah sebagai muatan lokal wajib di jawa timur, hanya ada Bahasa Madura dan Bahasa Jawa. Peraturan gubernur tersebut tidak menyertakan Bahasa Using sebagai muatan lokal wajib baik di SD/SMP Maupun SMA. Hingga saat ini pernyataan bahwa Bahasa Using berdiri sendiri dan bukan merupakan salah satu bagian dari dialek jawa masih menjadi perdebatan. Hal ini karena diperkirakan 70\% dari Bahasa using tersebut memiliki kosa kata yang mirip dengan Bahasa Jawa. Penuturan Bahasa Using jika dalam Bahasa jawa lebih terdengan seperti Bahasa jawa yang cenderung kasar (ngoko), seperti penggunaan kata "cangkem" (artinya mulut) dalam bahasa jawa tidak lazim digunakan karena terdengar sangat kasar. Hal ini didukung dengan temuan penelitian oleh Budiono, (2018), yang menunjukkan bahwa ada kemiripan secara linguistik Bahasa jawa Banyumas dengan Bahasa Using berdasarkan berkas isogloss, perhitungan dialektometri dan persamaan leksikal. Hal ini semakin membuat posisi Bahasa Using di pertanyakan kedudukannya sebagai sebuah Bahasa yang berdiri sendiri

Upaya memperjuangkan Bahasa Using sebagai Bahasa daerah melalui perjalanan yang cukup panjang. Menurut Arps, (2010:230) Bahasa using sendiri mulai di tampilkan sebagai Bahasa yang berdiri sendiri dalam sarasehan Bahasa Using pada tahun 1990. Selanjutnya dikeluarkanlah karangan-karangan dan dipresentasikan beberapa makalah yang selanjutnya menghasilkan pengajaran Bahasa Using pertama yaitu pada tahun 1997. Upaya pengukuhan bahasa Using menjadi bahasa yang berdiri sendiri tersebut kemudian dilakukan dengan menerbitkan kamus Bahasa Using- Indonesia, penentuan tata Bahasa baku dan buku pelajaran pada rentang tahun 1997-2002. Selanjutnya disusunlah pembuatan pedoman umum Bahasa Using pada tahun 2008 oleh dewan kesenian blambangan (Boediono, 2016:74). Tokoh yang sangat berpengaruh terkait penguatan Bahasa Using sebagai Bahasa daerah Banyuwangi adalah Hasan Ali, hingga kini kamus Using-Indonesia masih dikenal sebagai kamus Hasan Ali sebagai pelopor di susunya kamus tersebut. Upaya penguatan Bahasa Using sebagai Bahasa daerah khas Banyuwangi ini kemudian dilakukan dengan dikeluarkannya perda banyuwagi tahun 2007 yang 
Karimatus, Rima, Pemahaman Siswa Terhadap Pembelajaran. menyatakan bahsa Bahasa Using merupakan muatan lokal wajib untuk sekolah dasar dan menengah. Secara khusus dilakukan bimbingan teknis terkait pembelajaran Bahasa using di kelas terutama pada tingkat sekolah dasar.

Kebijakan muatan lokal Bahasa Using ini juga berlaku di SDN 1 Sumberbaru. SDN 1 Sumberbaru terleta di desa Sumberbaru kecamatan Singojuruh kabupaten banyuwangi. Desa sumberbaru merupakan desa hasil pemekaran dari desa kemiri, sehingga dapat dikatakan desa ini masih baru berdiri. Mayoritas penduduk di desa ini merupakan Orang Using. Siswa yang bersekolah di SDN Sumberbaru mayoritas juga merupakan orag asli yaitu anak-anak dari Orang using, namun dalam kesehariannya para siswa berkomunikasi menggunakan Bahasa jawa dan Bahasa Using.

\section{METODE PENELITIAN}

Sesuai dengan hasil bimbingan teknis bagi guru muatan lokal Bahasa using untuk sekolah dasar kabupaten Banyuwangi tahun 2019, materi Bahasa using terdiri dari ejaan, tata Bahasa baku Bahasa using dan sastra using. Sastra Using sendiri di bagi menjadi lima bagian yaitu basanan (Pantun), wangsalan, paribasan (Peribahasa), batakan (tebakan), dan guritan (puisi). Ejaan dan tata bahasa pada bahasa Using dapat dikatakan mirip dengan tata bahasa dalam bahasa jawa, hanya saja bahasa Using tidak memiliki tingkatan bahasa. Dari hasil observasi di SDN 1 Sumberbaru, bahasa jawa dan bahasa Using digunakan hampir bersamaan oleh siswa, sehingga bahasa Using lebih terdengar seperti bahasa jawa dengan dialek khas Banyuwangi.

Melalui muatan lokal bahasa Using, pemerintah kabupaten banyuwangi berusaha untuk menguatkan bahasa Using sebagai bahasa daerah banyuwangi agar siswa lebih mengenal bahasa daerah, dan harapannya lebih jauh semakin banyak penutur bahasa using di masa depan. Sehingga Penelitian ini bertujuan untuk mengetahui: 1) proses pembelajaran bahasa Using di SDN 1 Sumberbaru 2) kurikulum dan capaian kompetensi yang diharapkan pada pembelajaran bahasa Using Serta, 3)pemahaman siswa terhadap pembelajaran bahasa Using.

Sesuai dengan tujuannya yaitu mengetahui pelaksanaan pembelajaran bahasa Using di SDN1 Sumberbaru, maka penelitian ini menggunakan pendekatan kualitatif dengan design penelitian etnografi. Menurut (Creswell, 2012) desain etnografi merupakan bagian dari prosedur penelitian kualitatif untuk mendeskripsikan, menganalisis, dan menginterpretasikan budaya dalam suatu kelompok dengan pola perilaku bersama dari 
Karimatus, Rima, Pemahaman Siswa Terhadap Pembelajaran. sebuah kebiasaan, kepercayaan dan bahasa yang berkembang sepanjang waktu. Penelitian ini menggunakan tipe studi kasus di SDN 1 Sumberbaru 2 yang mayoritas siswanya merupakan Orang Using.

Penelitian ini dilaksanakan di SDN 1 Sumberbaru khususnya pada pembelajaran bahasa Using di kelas V. Pemilihan lokasi penelitian dilakukan dengan mempertimbangkan bahwa sekolah tersebut berdiri di dalam komunitas Orang Using, sehingga sangat kental dengan bahasa Using sebagai alat komunikasi sehari-hari. Subjek penelitian ini adalah siswa kelas V di SDN 1 Sumberbaru kecamatan Singojuruh kabupaten Banyuwangi.

Pengambilan data dilakukan melalui teknik observasi, wawancara dan pengambilan dokumen. Teknik observasi digunakan untuk mengambil data tentang kegiatan pembelajaran bahasa Using yang dilaksanakan di kelas, serta mengobservasi bagaimana bentuk komunikasi antar siswa dalam kegiatan pembelajaran tersebut. Teknik wawancara dilakukan untuk mengetahui pemahaman siswa dalam pembelajaran bahasa Using yang dilaksanakan di kelas. Pengambilan dokumen dilakukan untuk mengetaui data yang valid terkait hasil tes siswa pada mata pelajara bahasa Using sehingga dapat memperkuat data tentang pemahaman siswa terhadap pembelajaran Bahasa Using..

Data yang di peroleh melalui beberapa teknik tersebut kemudian diolah sehingga mengahsilkan suatu kesimpulan penelitian yang relevan. Menurut Jhonson \& Cristensen (Dalam Hanurawan, 2012)) dalam penelitian etnografi teknik analisis data dilakukan dengan deskripsi secaara menyeluruh dan pencarian tema-tema yang terkait dengan budaya atau kultur yang diteliti pada data yang dikumpulkan. Analisis data dilakukan secara simultan yang artinya ketika pengambilan data dan analisis data dirasa ada yang kurang, maka dapat dilakukan pengambilan data lagi di lapangan untuk melengkapi kemudian dilakukan analisis lagi begitu seterusnya hingga dapat menjawab tujuan penelitian.

Teknik analisis data yang dilakukan dalam penelitian ini adalah pengumpulan data, reduksi data, revisi data, analisis data dan penarikan kesimpulan. Data yang telah diperoleh melalui teknik pengumpulan data kemudian di reduksi yaitu dipilah mana yang relevan dengan penelitian dan data mana yang tidak sesuai, Setelah itu data direvisis sesuai dengan kebutuhan penelitian, artinya data yang telah direduksi jika dirasa masih membutuhkan data tambahan maka dapat dilakukan pengambilan ulang data di lapangan. 
Karimatus, Rima, Pemahaman Siswa Terhadap Pembelajaran.

Data kemudian dianalisis sesuai dengan masalah dan tujuan penelitian yang telah dirumuskan sebelumnya. Terakhir dilakukan penarikan kesimpulan sesuai dengan tujuan penelitian yang telah ditetapkan.

\section{HASIL DAN PEMBAHASAN}

\section{Proses pembelajaran Bahasa Using di Kelas}

Pembelajaran bahasa Using dilaksanakan pada hari jumat dari pukul 07.00- 09.00. Akan tetapi jadwal pembelajaran bahasa Using dalam pelaksanaannya dilaksanakan berselang-seling dengan bahasa jawa, artinya bahasa using tidak di ajarkan setiap minggunya, namun sekitar dua kali pertemuan dalam satu bulan. Sebelum dilksanakan pembelajaran Bahasa Using, sebelumnya guru telah diberikan pembekalan terkait kurikulum, kompetensi dan materi apa saja yang harus di ajarkan di sekolah dasar. Ketika pembelajaran di kelas guru juga di bekali modul atau buku yang berisi panduan kegiatan belajar, materi dan tugas tugas yang harus dilaksanakan oleh siswa, sal-soal beserta kunci jawabannya.

Pelaksanaan kegiatan pembelajaran dikelas khususnyadikelas V dilaksanakan dengan menggunakan metode ceramah serta penugasan. Metode ceramah digunakan untuk menjelaskan tentang aspek-aspek sastra dan kebahasaan yang harus dikuasai oleh siswa. Sedangkan penugasan digunakan untuk materi yang berkaitan dengan melatih kemampuan siswa membaca dan menjawab pertanyaan siswa dalam Bahasa Using.

Jika dilihat secara umum, tidak semua guru menguasai Bahasa Using karena beberapa guru merupakan pendatang dan bukan asli Orang Using. Sehingga proses pembelajaran kadang terlihat terlalu bergantung pada buku panduan yang telah di berikan. Guru masih belum mampu mengeksplorasi lebih jauh baik dari segi materi maupun metode yang digunakan, karena beberapa guru yang memang bukan asli Orang Using juga masih berusaha mendalami materi Bahasa Using tersebut.

Pelaksanaan pembelajaran yang hanya dilaksanakan dua minggu sekali membuat pembelajaran Bahasa Using tidak dapat di laksanakan secara maksimal, karena kadang siswa lupa dengan materi yang telah diajarkan dua minggu sebelumnya. Pembelajaran Bahasa Using dilaksanakan berselang seling dengan Bahasa jawa kadang juga membuat siswa bingung, karena secara struktur Bahasa Using dan Bahasa Jawa hampir mirip pada beberapa kosa katanya. Namun dalam komunikasi sehari-hari siswa yang merupakan 
Karimatus, Rima, Pemahaman Siswa Terhadap Pembelajaran.

Orang Using maupun dari luar Orang Using dapat saling mengerti Bahasa masing-masing dengan baik, walaupun keduanya berbicara dalam Bahasa Using dan Bahasa Jawa.

Guru (Kelas V) menyatakan bahwa siswa dalam berkomunikasi atau keterampilan berbicara cukup fasih menggunakan Bahasa Using, namun dalam kegiatan pembelajaran, seperti pada kegiatan pembelajaran pada umumnya mereka tidak seluruhnya mampu atau dapat dikatakan sangat menguasai pembelajaran tersebut walaupun mereka merupakan Orang asli. Karena ada aspek-aspek kebahasaan yang masih jarang di ketahui oleh siswa terutama pada aspek sastra Using. Guru masih membutuhkan pelatihan lebih lanjut terkait Bahasa Using agar pembelajaran dapat dilaksanakan lebih bermakna dan mampu mencapai kompetensi.

\section{Kurikulum Pembelajaran Bahasa Using}

Sesuai dengan panduan kurikulum yang diterbitkan dinas pendidikan kabupaten Banyuwangi tahun 2019, Penyusunan kurikulum Bahasa Using dilakukan dengan pertimbangan bahwa Bahasa Using dianggap merupakan kebudayaan khas Banyuwangi dan sebagai identitas Banyuwangi, sehingga keberadaannya perlu di pertahankan. Penyusunan kurikulum ini juga mempertimbangkan bahwa terdapat kecenderungan menurunnya jumlah penutur Bahasa Using di kalangan generasi muda, sehingga perlu adanya kurikulum khusus untuk mengajarkan Bahasa Using sejak dini yaitu di tingkat sekolah dasar. Mata pelajaran bahasa Using merupakan program muatan local yang bertujuan untuk mengembangkan pengetahuan, keterampilan berbahasa dan sikap positif terhadap Bahasa daerah.

Secara umum fungsi pembelajaran bahasa Using adalah sebagai sarana pembinaan dan pelestarian budaya, peningkatan pengetahuan dan keterampilan untuk menggali dan mengembangkan ilmu pengetahuan dan teknologi serta kesenian khas Banyuwangi. Selain itu juga sebagai sarana penyebarluasan penggunaan bahasa Using untuk berbagai keperluan. Secara khusus Bahasa Using di ajarkan kepada siswa sekolah dasar agar salah satunya siswa dapat menghargai dan membanggakan Bahasa Using sebagai unsur budaya nasional.

Ruang lingkup pembelajaran Bahasa Using di sekolah dasar meliputi penguasaan, kebahasaan, kemampuan memahami, mengapresiasikan sastra dan kemampuan menggunakan Bahasa Using. Struktur kurikulum bahasa Using mengikuti kurikuum 2013. Terdapat kompetensi Inti dan kompetensi dasar yang harus di capai oleh siswa. 
Karimatus, Rima, Pemahaman Siswa Terhadap Pembelajaran.

Kompetensi inti dibagi menjadi empat bagian. Kompetensi inti pertama mengandung muatan sikap spiritual yang harus dikuasai siswa, kompetensi inti kedua mengandung muatan sikap sosial seperti perilaku jujur, disiplin santun, percaya diri dan bertanggung jawab. Kompetensi Inti ketiga memuat aspek pengetahuan dan kompetensi iti keempat memuat aspek keterampilan yang harus di kuasai oleh siswa.

Pada kompetensi dasar yang dikembangkan hanya memuat aspek dari kompetensi inti ketiga yaitu aspek pengetahuan dan kompetensi inti keempat yaitu aspek keterampilan. Kompetensi dasar khususnya di kelas V dibagi menjadi dua yaitu untuk semester 1 dan semester 2. Masing masing semester terdapat tiga kompetensi dasar aspek pengetahuan dan 3 kmpetensi aspek keterampilan yang harus dicapai. Kurikulum pembelajaran Bahasa Using ini diperuntuukan bagi siswa kelas IV,V, dan kelas VI. Artinya mata pelajaran Bahasa Using ini hanya di ajarkn di kels tinggi saja.

Materi yang disajikan di kelas 5 diantaranya dapat dilihat pada tabel berikut.

Tabel materi pembelajaran Bahasa using kelas V

\begin{tabular}{|c|c|}
\hline Semester 1 & Semester 2 \\
\hline $\begin{array}{l}\text { - Pertanyaan dan pemaparan cara, urutan } \\
\text { pembuatan makanan khas Banyuwangi } \\
\text { - Kosa Kata macam-macam makanan } \\
\text { khas Banyuwangi } \\
\text { - Pantun } 4 \text { baris }\end{array}$ & 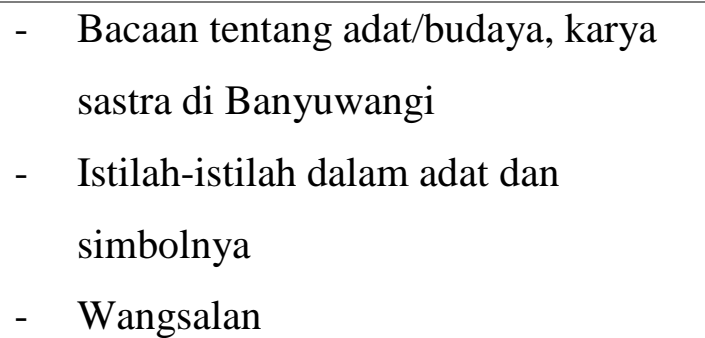 \\
\hline $\begin{array}{l}\text { - Bacaan tentang Festival kesenian di } \\
\text { Banyuwangi } \\
\text { - Kata majemuk dan kata sifat } \\
\text { - Peribahasa }\end{array}$ & $\begin{array}{l}\text { - Petanyaan dan meringkas bacaan } \\
\text { - Mengenal nama tokoh dan bidangnya } \\
\text { dalam percakapab } \\
\text { - Puisi "Isum Lare Using" }\end{array}$ \\
\hline $\begin{array}{l}\text { - Bacaan tentang perangkat kesenian } \\
\text { tradisional Banyuwangi } \\
\text { - Kalimat Tanya } \\
\text { - Menyanyikan lagu "Umbul-Umbul } \\
\text { Blambangan" }\end{array}$ & $\begin{array}{l}\text { - menyususn pertanyaan setelah } \\
\text { diketahui jawaannya } \\
\text { - tanya jawab menggunakan basa } \\
\text { (Besiki) } \\
\text { - Bermain drama dengan naskah yang } \\
\text { telah disediakan }\end{array}$ \\
\hline
\end{tabular}


Karimatus, Rima, Pemahaman Siswa Terhadap Pembelajaran.

Berdasarkan materi yang telah di jabarkan tersebut, menunjukkan bahwa kompetensi pembelajaran bahsa Using mencakup semua aspek keterampilan berbahasa, dengan mengedepankan kajian dan tema tentang kehasan lokal banyuwangi. Pembelajaran bahasa Using ini memiliki misi untuk melestarikan dan memperkenalkan budaya Banyuwangi agar generasi muda khususnya siswa SD dapat ikut melestarikan kebudayaan Banyuwangi. Hal ini dapat dilihat pada masingimasing materi yang di tampilkan yaitu memasukkan unsur, kesenian, makanan tradisional maupun kegiatan yang berkaitan dengan kekhasan Banyuwangi.

\section{Pemahaman Siswa Terhadap Bahasa Using}

Berdasarkan hasil observasi dilapangan kebanyakan siswa yang merupakan suku Using, menggunakan bahas Using dalam percakaan dengan teman sebaya.. Akan tetapi hal ini berbeda dengan kegiatan pembelajaran di kelas. Hasil wawancara dengan guru menyatakan bahwa siswa kurang dapat memahami pembelajaran Bahasa Using, bahkan jika kita membuat perbandingan lebih mudah mempelajari Bahasa Using atau Bahasa Indonesia, maka jawabannya adalah lebih mudah mengajarkan Bahasa Indonesia dari pada Bahasa Using kepada siswa. Terkadang siswa merasa asing dengan beberapa pilihan kosa kata dalam bacaan. Berbeda dengan pembelajaran Bahasa Indonesia, siswa lebih mudah memahami bacaan. Dari seluruh aspek Bahasa, aspek sastra dianggap sebagai aspek yang paling susah untuk diajarkan dan dipahami oleh siswa.

Hal ini diperkuat dengan hasil ujian tengah semester gasal tahun ajaran 2019/2020 (yang asli sebelum dilaksanakan proses remedial) menunjukkan bahwa nilai rata-rata Bahasa Using siswa kelas V adalah 39 sedangkan ketuntasan minimal yang harus di capai oleh siswa adalah 75. Nilai terendah adalah 7 sedangkan nilai tertinggi dalam satu kelas adalah 64. Kompetensi yang diujikan saat ujian tengah semester adalah tentang bacaan, sastra using yang meliputi Basanan (pantun), geguritan (puisi) unen-unen (Peribahasa), wangsalan, spengetahuan seputar budaya Banyuwangi dan membuat karangan dalam Bahasa Using. Rata-rata nilai rendah diperoleh siswa pada pertanyaan tentang sastra, dan pengetahuan seputar budaya Banyuwangi.

Penyusunan soal penilaian tengah semester di ambil dari materi yang terdapat dalam buku teks Bahasa Using, artinya soal-soal yang di ujikan telah diajarkan atau dipelajari oleh siswa sebelumnya. Nilai siswa seluruhnya di bawah kriteria ketuntasan minimal tidak serta merta menunjukkan bahwa pemahaman siswa sangat rendah atau 
Karimatus, Rima, Pemahaman Siswa Terhadap Pembelajaran. siswa sama sekali tidak bisa bahasa Using. Ada faktor-faktor yang mungkin menjadi penyebab rendahnya hasil ujian tersebut seperti misalnya ketidaksiapan siswa mengikuti ujian, metode pembelajaran yang masih perlu disesuaikan, serta kompetensi siswa yang heterogen. Akan tetapi hasil wawancara dan observasi memang menunjukkan bahwa siswa masih lemah dalam memahami Bahasa Using secara tekstual yang diajarkan di kelas walaupun dapat berkomunikasi secara aktif dalam percakapan sehari-hari.

Salah satu faktor penyebab sulitnya siswa memahami Bahasa Using dikarenakan guru sendiri juga belum mampu memahami struktur Bahasa Using itu sendiri, sehingga belum menemukan metode yang sesuai untuk mengajarkan Bahasa Using pada siswa. Selain itu Bahasa Using sebagai alat komunikasi lebih sederhana berbeda dengan Bahasa Using sebagai sebuah tata Bahasa yang didalamnya terdapat unsur sastra dan struktur Bahasa tertentu. Struktur Bahasa tersebut masih asing bagi siswa. Faktor lain yang dapat menjadi penyebab perbedaan ini adalah karena siswa juga menggunakan Bahasa jawa dalam pergaulan antar siswa maupun kepada guru. Hal ini karena tidak semua guru merupakan suku Using, sehingga komunikasi sehari-hari tidak murni menggunakan Bahasa Using, akan tetapi bercampur dengan Bahasa Jawa.

Terlepas dari masih belum maksimalnya pelaksanaan pembelajaran Bahasa Using di sekolah dasar, namun upaya untuk melestarikan Bahasa Using melalui pembelajaran merupakan sebuah langkah yang tepat. Melalui Bahasa Using, siswa dapat lebih mengenal Budaya Banyuwangi yang mungkin tidak muncul pada pembelajaran lain. Bahasa Using beserta budaya yang melekat dalam masyarakat Using merupakan warisan budaya lokal yang perlu di pelajari oleh siswa. Upaya pewarisan budaya melalui pendidikan ini juga merupakan bagian dari penguatan nilai-nilai karakter siswa yang bersumber dari budaya lokal. Sehingga upaya penyempurnaan kurikulum Bahasa Using serta pelatihan pembelajaran Bahasa Using harus terus dikembangkan.

\section{SIMPULAN}

Pelaksanaan pembelajaran Bahasa Using di kelas khususnya kelas V SDN 1 Sumberbaru dilaksanakan dua minggu sekali setiap hari jumat berselang-seling degan pembelajaran Bahasa Jawa. Pada pelaksanaan pembelajaran, guru dibekali dengan kurikulum dan buku panduan Bahasa Using. Metode pembelajaran yang digunakan yaitu ceramah dan penugasan. Struktur kurikulum pembelajaran Bahasa Using di SD mengikuti kurikulum 2013. Materi yang dibelajarkan yaitu tentang, tata Bahasa using, wacana yang 
Karimatus, Rima, Pemahaman Siswa Terhadap Pembelajaran.

memuat tentang budaya orang Using, sastra Using. Berdasarkan hasil wawancara, dan hasil penilaian tengah semester, dapat disimpulkan bahwa siswa masih kurang mampu memahami pembelajaran Bahasa Using walaupun mereka dapat berkomunikasi secara aktif. Hal ini diperkuat dengan nilai rata-rata hasil penilaian yaitu sebesar 39. Aspek yang masih belum di pahami oleh siswa adalah pada aspek sastra Using serta pengetahuan mengenai budaya Using. faktor penyebabnya adalah ada beebrapa guru yang bukan orang asli Using sehingga masih mempelajari dan mengembangkan metode pembelajaran yang tepat serta struktur Bahasa Using yang ditampilkan dalam pembelaaran masih di rasa asing bagi siswa.

\section{DAFTAR RUJUKAN}

Arps, B. (2010). Terwujudnya Bahasa Using di Banyuwangi. In M. Moriyama \& M. Budiman (Eds.), Terwujudnya Bahasa Using di Banyuwangi dan Peranan Media Elektronik di Dalamya (Selayang Pandang 1970-2009). tokyo: Research Institute For language and Culture of Asia and Africa, Tokyo University of Foreign Studies. Bahtiar, Syamsu Hadi, S. D. (2018). Pendidikan Budaya dan Sejarah "Dibalik Revitalisasi Budaya." Budaya Gagas Peri Suku Osing Di Banyuwangi, 24-34. https://doi.org/10.31227/osf.io

Budiono, S. (2018). Penelusuran Identitas dan Bahasa Masyarakat Banyuwangi Berdasarkan Kesamaan Leksikal Kosakata Jawa Kuno di Banyumas Dan Banyuwangi. Sirok Bastra, 6(2), 205-210.

Creswell, J. W. (2012). Educational research, Planning, Conducting, And Evaluating Quantitative And Qualitative Research (4th ed.). pearson.

Damariswara, 2016. Analisis Ketidaktepatan Penggunaan Bahasa Jawa Krama Alus Mahasiswa Pgsd Angkatan 2012 UN PGRI Kediri Dalam Mata Kuliah Bahasa $\begin{array}{llll}\text { Daerah. Jurnal Pendidikan Dasar } & \text { Nusantara }\end{array}$ .https://ojs.unpkediri.ac.id/index.php/pgsd/article/view/341

Hanafi, H., Hidayah, N., \& At, A. M. (2018). Adopsi Nilai Budaya Osing dalam Kerangka Objektivitas Meaning of Life. Jurnal Pendidikan, 3(9), 1237-1243.

Hanurawan, F. (2012). Qualitative Research In Psychology. Journal of Educational Health And Community Psychology, 1(2).

Saputra, H. S. P. (2007). Memuja Mantra; Sabuk Mangir dan Jaran Goyang Masyarakat 
Karimatus, Rima, Pemahaman Siswa Terhadap Pembelajaran. Suku Using Banyuwangi. yogyakarta: LKIS Pelangi Aksara.

Sutarto, A. (2006). Sekilas Tentang Masyarakat Using. Makalah disampaikan pada acara pembekalan Jelajah Budaya 2006 yang diselenggarakan oleh Balai Kajian Sejarah dan Nilai Tradisional Yogyakarta, tanggal 7 - 10 Agustus 2006. 2 